\title{
Planejamento de carreira: Uma orientação para universitários
}

\author{
Career planning: A guide for college students
}

Maria Sara de Lima-Dias ${ }^{[0]}$, Dulce Helena Penna Soares ${ }^{[b]}$

${ }^{[a]}$ Doutora em Psicologia pela Universidade Federal de Santa Catarina (UFSC), Departamento de Psicologia da Universidade Tuiuti do Paraná (UTP), Curitiba, PR - Brasil, e-mail: maria.dias@utp.br

${ }^{[b]}$ Doutora em Psicologia Clínica na Universidade Louis Pasteur em Strasbourg, Departamento de Psicologia da Universidade Federal de Santa Catarina (UFSC), Florianópolis, SC Brasil, e-mail: dulcepenna@ terra.com.br

Recebido: 06/04/2010 Received: 04/06/2010

Aprovado: 29/09/2010 Approved: 09/29/2010

\section{Resumo}

Este artigo discorre sobre o planejamento de carreira de universitários, e tem como objetivo atender a necessidade dos alunos de apoio psicológico para a fase da transição da universidade para o mundo do trabalho. A indecisão sobre qual caminho seguir após o período universitário é frequente para os estudantes e se caracteriza como um momento permeado de dúvidas, inseguranças e angústias sobre o futuro. A complexidade do trabalho flexível exige das instituições de ensino superior comprometimento com os egressos e uma preparação para os riscos imponderáveis do contexto profissional. A proposta de uma disciplina de Orientação Profissional, para alunos formandos de uma universidade pública, culminou com a publicação pelas autoras de um livro intitulado Planejamento de Carreira: Uma orientação para estudantes universitários. Este apresenta uma metodologia específica para auxiliar os estudantes a planejar suas carreiras e possibilita à universidade oferecer um apoio objetivo nesse processo. A disciplina aborda as temáticas da escolha da profissão, o conhecimento de si, o entendimento dos anos universitários, as realidades do mercado de trabalho e da inserção profissional, através de exercícios de dinâmicas de grupo e técnicas de planejamento de carreira. A experiência na disciplina demonstra que o apoio psicológico é fundamental na inserção dos estudantes no mundo do trabalho.

Palavras-chave: Planejamento. Carreira. Transição. Universidade. Orientação profissional.

\begin{abstract}
This study focused on university students' career planning aims to meet the needs of students for psychological support for the phase of transition from university to the world of work. The development of this subject indicates that indecisions about which way to go after graduating is common for college students and it is characterized as a time permeated by doubts, insecureness and anxieties about the future. The complexity of work requires of institutions of higher education a commitment with the graduates and preparation for the immeasurable risks of the professional context. The proposal of a professional guidance subject for senior college students of a public university culminated with the publication, by the authors of the idea, of a book entitled “Career Planning: a guide for college students", which presents a specific methodology that helps students to plan their careers and allows for the university to offer an objective support in
\end{abstract}


this process. The course addresses the issues of careers choices, knowledge itself, understanding college years and the realities of the work market and job placement, through group dynamics exercises and career planning techniques. The experience acquired from this subject has shown that psychosocial support is essential for the integration of students in the world of work.

Keywords: Career. Planning. Transition. University. Vocational guidance.

\section{Sobre o planejamento de carreira na universidade}

O planejamento de carreira na universidade objetiva atender à necessidade dos estudantes de apoio psicológico para a fase da transição onde as escolhas de carreira estão em jogo. 0 tempo de formação e estudo do aluno, o seu empenho de qualificação para o trabalho, deve ser adequado ao seu perfil e ao desenvolvimento de suas habilidades, interesses e atitudes para a inserção do sujeito no trabalho (Sposito, 1989).

Constata-se a complexidade do mundo do trabalho ao abordar a questão das carreiras, uma vez que os sistemas de organização do trabalho que introduziram o taylorismo e o fordismo (Antunes, 2007) afirmam mudanças cada vez maiores e mais rápidas na economia. Mudanças tecnológicas na produção e transmissão de conhecimentos e a mundialização dos negócios sofrem uma dupla contestação: a exigência de respostas alternativas a estas transformações sócioculturais e o questionamento profundo do ensino tal como é desenvolvido hoje nos centros de formação (Chanlat, 1996; Ferreti, 1988, 1989, 2004; Martins, 2006).

Através do planejamento de carreira pretendeu-se orientar os alunos no sentido de compreender a complexidade do mundo do trabalho, e analisar o tempo e os investimentos necessários em seu potencial enquanto estudantes universitários, para se dedicarem ao desenvolvimento de uma carreira profissional futura (Super, 1957).

No Brasil, mesmo os estudantes que chegam ao grau de escolarização superior se deparam com vários desafios para se graduarem em uma carreira e enfrentarem a transição da universidade para o mercado de trabalho (Sparta, 2003).

Observou-se, por exemplo, a contratação de pessoas muito mais qualificadas do que a real necessidade do conteúdo dos postos de trabalho, uma redução do emprego assalariado e estável e um maior desemprego e subemprego para os jovens (Antunes,
2007; Dowbor, Furtado, Trevisan \& Silva, 2004; Pochmann, 2000; Soares, Krawulki, Dias \& D’Àvila, 2007). Com jornadas sobrepostas ou trabalho insuficiente assim existe uma desvalorização do emprego tradicional (Antunes, 2007; Dowbor et al., 2004).

As carreiras tradicionais para as quais os jovens se preparavam e que eram destinadas a realizar atividades técnicas repetitivas avançam lentamente ou estão desaparecendo, assim como a utilização de um único conjunto de qualificações durante toda a vida do sujeito no trabalho. Em decorrência disso, os estudantes que eram preparados para uma única carreira durante toda a vida estão sendo ignorados no mundo do trabalho, pois este exige competências multidisciplinares, e aumentam as angústias declaradas pelos alunos nessa transição (Dias \& Soares, 2009):

não sei agora o que vou fazer da vida! Será que devo investir na educação ou optar pelo ingresso imediato! Será que volto para a casa dos meus pais ou me mudo para um grande centro urbano onde existem melhores oportunidades de trabalho?

Esses questionamentos carregados de ansiedade dos alunos mobilizaram a Universidade a criar uma disciplina Orientação e Planejamento de Carreira e também escrever o livro: Planejamento de Carreira: uma orientação para estudantes universitários (Dias \& Soares, 2009). Nesse livro as falas dos jovens são inseridas ao longo do texto, recolhidas durante os anos em que uma das autoras foi professora desta disciplina na Universidade Federal de Santa Catarina (UFSC).

O material publicado no livro está sendo utilizado e aplicado a mais de 20 turmas, desde que foi criada a disciplina em 2003, com o objetivo de discutir e trabalhar a inserção dos graduandos no mercado de trabalho através do planejamento de carreira. A disciplina atende alunos de todas as áreas de conhecimento, e a heterogeneidade dos grupos permite desenvolver o crescimento pessoal e 
profissional de outras áreas do saber que de outro modo não eram acessíveis aos alunos. São preparados para a compreensão do conceito de carreira como a sequência indefinida de experiências de trabalho vivenciadas ao longo do tempo pelos sujeitos.

No livro abordam-se conteúdos teóricos sobre o que é o mundo do trabalho, o que são profissões, qual o sentido do trabalho na subjetividade humana (Antunes, 2007; Vygotsky, 2000), e buscando desvendar caminhos possíveis e estratégias de desenvolvimento de carreira. Não se trata de um livro de regras e normas a serem comodamente cumpridas e que podem milagrosamente trazer a satisfação e tranquilidade necessária aos jovens (Dias \& Soares, 2009).

Na segunda parte do livro apresentam-se recursos e instrumentos, a fim de auxiliar professores e formandos a refletirem sobre as opções possíveis neste universo complexo, onde muitas vezes o jovem se sente vítima do desemprego e das mazelas de ter um diploma em uma sociedade sem muitas oportunidades para o jovem diplomado (Antunes, 2007; Fonseca, 2007).

As ansiedades repercutem na formação de uma identidade profissional, como exemplificado nesta fala: "Eu vou deixar de fazer parte da elite estudantil e começar a fazer parte da massa de desempregados". A crise de identidade na transição tem reflexos imediatos no alargamento do tempo em que o jovem permanece na universidade, retardando o processo de entrada no mundo profissional, graças ao temor do desemprego. Compreende-se o sujeito como uma síntese aberta, em constante movimento de apropriação de aspectos da realidade, modificando concomitantemente a si mesmo e aquela realidade (Dias \& Soares, 2009).

Considerando que a universidade foi criada no Brasil nos anos 30 do século XX, apresenta-se com uma história muito curta e, portanto, com uma tradição ainda frágil, onde a escolha profissional não tem sido dada como uma opção ao jovem.

A escolha profissional vem sendo diluída pela falta de oportunidades reais (Soares, 2002). Pretendeu-se com o livro possibilitar aos universitários uma reflexão sobre o projeto profissional, através do planejamento de carreira, pois se acredita na possibilidade do sujeito reflexivo e positivo ser o autor de sua história e de seu destino.

Existe uma necessidade de repensar os valores subjetivos e identificar o quanto estes valores encontram-se inter-relacionados, para que o trabalho possa significar uma possibilidade de autorrealização e de desenvolvimento pessoal e social (Lane, 2001). Assim o autoconhecimento é de suma importância para a realização da condição humana em sua plenitude possível, e é um dos assuntos abordados e desenvolvidos nos grupos de planejamento de carreira. Muitos alunos nos dizem: "Eu não sei o que gosto de fazer, posso gostar de qualquer atividade, ou creio que poderia ser qualquer profissional no futuro, na verdade não sei". Desconhecem assim quais são suas habilidades, atitudes e interesses, suas competências e o que têm de fato para ofertar em termos de conhecimentos teóricos e práticos para o mercado de trabalho.

O mercado de trabalho está em constante mudança e existem várias condições que promovem esta oscilação constante do mesmo. Entre elas a evolução tecnológica e a globalização são alguns fatores que influenciam no surgimento ou desaparecimento de profissões. As oportunidades mudam de lugar, ou são instáveis conforme oscilações do mercado, aumentando a angústia dos formandos, que nos dizem: "Agora o mercado oferece mais oportunidades para Engenheiro de Alimentos, porque eu fui fazer nutrição! Sei que na minha área de Farmácia eu vou passar o resto da vida a trás de um balcão, não sabia disto quando escolhi o curso superior!". Entre arrependimentos e satisfações os alunos saem do contexto universitário, muitos em busca do emprego na indústria, porém, segundo Pochmann sobre a batalha pelo primeiro emprego, "hoje 70\% dos empregos gerados são do setor terciário, e até 2030 o percentual chegará a 90\%" (Pochmann, 2000, p. 23).

Muitos escolheram os cursos superiores, sem apoio ou orientação profissional que os auxilie na entrada do mundo universitário. A saída não é diferente, não sabem qual caminho seguir, mostram-se, inseguros e os índices de abandono e evasão permanecem altos, mesmo nas universidades federais, públicas e gratuitas. 0 medo do mercado de trabalho se transforma em um fantasma que assombra os jovens na saída do contexto universitário (Dias \& Soares, 2009).

Segundo Soares, "com todo o alarde por causa da virada do século, a preocupação tem sido em razão das profissões que surgirão daqui para frente, as profissões do futuro" (Soares, 2002, p. 115). Observam-se mudanças na conduta dos universitários na procura por se adequar a um determinado perfil dos profissionais inseridos num universo 
de trabalho de permanente transformação. Muitos jovens são o que se pode chamar de superqualificados, procuram se adequar aos ditames do mercado: "Estou fazendo aula de Chinês porque ouvi dizer que é a língua do futuro". Os jovens buscam a adaptação ao mercado e estão ansiosos por fazerem parte da escrita de uma história pessoal de sucesso. Porém a maioria investe seus recursos sem produzir uma mínima reflexão crítica sobre o processo da escolha de carreira evidenciando-se, portanto, a necessidade de abordar o planejamento de carreiras nas universidades.

\section{Desenvolvimento: o porquê planejar a carreira}

Os motivos anteriormente descritos nos revelam aumento dos investimentos familiares na educação para o emprego. A temática da qualificação e da empregabilidade tem atraído milhares de jovens para a realização de cursos de curta duração que visam complementar sua formação (Dowbor et al., 2004; Dutra, 2002; Pochmann, 2000). Mas nem sempre tais cursos estão direcionados para o que o jovem deseja ser ou pretende escolher enquanto uma carreira.

Deve-se cuidar da orientação para que os recursos sejam realmente investidos em áreas do saber que permitam a integral formação do cidadão e para a realização plena de suas potencialidades.

O planejamento de carreira tem este objetivo de definir sobre uma base de autoconhecimento obtida através da participação em dinâmicas de grupo, discussões sobre o mundo do trabalho e sobre a transição. É necessário conceituar o que entendemos por planejamento de carreiras. A carreira é definida como a combinação e sequência de papéis desempenhados por uma pessoa durante o curso de uma vida. As funções incluem várias posições e papéis sociais: aqueles de criança, aluno ou estudante, cidadão trabalhador, esposo, dona de casa, mãe, e outros cargos associados (Dutra, 2002). A carreira não deve ser tratada como uma sequência linear de experiências e é fruto da relação e das necessidades de indivíduos e organizações.

Acredita-se numa gestão compartilhada de carreira entre a empresa e a pessoa, com critérios de ascensão desvinculados de uma estrutura organizacional rígida e cada vez mais enxuta, nos tempos modernos, é fundamental para a permanência do capital intelectual nas empresas (Dutra, 2002).
Existem dois tipos básicos de carreiras trazidas pela dinâmica da globalização: uma carreira externa oferecida pelo mercado de trabalho, objetiva, e uma carreira subjetiva. Porém, na carreira subjetiva, essa possibilidade de construção de uma carreira interna implica em um planejamento também objetivo que é decorrente de possibilidades e impossibilidades de ser alcançada em determinadas condições sociais e econômicas. Deve abordar a subjetividade, no sentido do desejo do sujeito, de suas motivações e anseios profissionais (Lane, 2000; Super, 1957). Sendo desenvolvida com o sujeito que, apesar dos aspectos objetivos (e das limitações), sempre terá condições de planejar um futuro pessoal e profissional.

Pensar o futuro pressuposto ou ansiado, e ao mesmo tempo traçar metas para atingir, condicionadas em etapas previstas e estrategicamente montadas que permitem facilitar a inserção do jovem e as várias transições neste mercado de trabalho. 0 objetivo principal desta proposta de planejamento de carreira é apresentar um modelo de orientação profissional, articulado entre a vida pessoal e profissional, em que o sujeito seja capaz de identificar suas competências, pontos fortes em termos de atitudes, habilidades e valores. E também que possa, através do detalhamento de seus objetivos e metas pessoais, se encaminhar profissionalmente para a realização pessoal e profissional, com um trabalho que esteja de acordo com suas expectativas e interesses de vida e carreira (Dias \& Soares, 2009).

No Brasil são poucos os trabalhos científicos que se produzem na área do planejamento de carreira, entre eles Dias \& Soares, (2009) e Dutra, (2002); no entanto em outros países, o planejamento de carreira é visto como um bem público, ligado aos objetivos da política relacionados à aprendizagem, ao mercado de trabalho e à equidade social. Estes objetivos estão sendo reformulados à luz de políticas da aprendizagem ao longo da vida, ligada às políticas de mercado de trabalho e à noção de empregabilidade. Assim, este trabalho necessita ser acessível não só aos níveis universitários, mas a todos os estudantes e profissionais durante ao longo de suas vidas.

Por outro lado, no mercado do trabalho atual, abriram-se várias vertentes na gestão de pessoas e que direcionam estratégias e práticas ainda não totalmente conhecidas ou exploradas de planejamento de carreira (Dias \& Soares, 2009). Empresas estrategicamente oferecem carreiras aos jovens, dentro de suas estruturas e organogramas, prevendo 
alguma estabilidade em seus quadros de funcionários, tornando-se um grande atrativo para os jovens (Dowbor et al., 2004). Como os processos de programas trainee dentro de bancos, indústrias ou grandes corporações, ilustrado na fala de nossos alunos:

Eu vou mesmo é entrar no Banco, eles precisam de engenheiros vou seguir a carreira administrativa e em cinco ou dez anos me tornar um Diretor Administrativo e Financeiro! - Eles preferem engenheiros mecânicos porque estes têm facilidade com a realização de cálculos e projeções.

Nesse caso, o jovem estudante de engenharia mecânica escolheria uma carreira bancária e sairia de sua área de conhecimento acadêmico. Cerca de 53\% dos jovens não atuam em sua área de formação profissional do Brasil, são dados divulgados pelo ex-presidente do Conselho Nacional de Educação (Nunes, 2006). 0 fato de estar ou não dentro de sua área de conhecimento não altera, no entanto a necessidade do planejamento de carreira.

Discutir amplamente as possibilidades futuras, e os riscos de suas escolhas, permite que o jovem vislumbre possibilidades diferentes, muitas vezes distantes do contexto universitário. Atuando através da orientação na facilitação do processo de escolha, alguns sucessos nos processos de planejamento evidenciam esta necessidade de reflexão das escolhas de carreira.

0 trabalho da orientação e planejamento de carreira exige uma formação profissional compatível com as novas demandas do mercado que ditam novas regras para a inserção ocupacional, onde novos conceitos como inteligência emocional, talentos, competências, procuram descrever e gerenciar o potencial e o capital intelectual dentro das empresas (Dowbor et al., 2004). Os profissionais que atuam neste campo devem conhecer amplamente as áreas de trabalho, as profissões e as carreiras que cada vez mais deixam de ser locais e passam a ser globais.

Ao mesmo tempo em que o orientador apoia e desenvolve o planejamento de carreira junto com o estudante, deve-se alertar de que a responsabilidade pela inserção e permanência no mercado de trabalho não deve recair somente sobre os formandos. As oscilações da macroeconomia promovem mudanças de lugares e postos profissionais e podem certamente surpreender os jovens neste período de transição. Assim é preciso planejar também as várias transições que ocorrem ao longo da vida profissional do sujeito.

Ingressar no mundo do trabalho e assumir as responsabilidades por suas escolhas faz com que os jovens se mostrem inseguros em tomar decisões, como nesta fala: "Não sei o que será do amanhã!"; "Posso trabalhar com qualquer coisa!"; "Depois de formado o que vier está bom". Assim as inúmeras exigências do mercado de trabalho se fazem sentir sobre os jovens que acabam aceitando os empregos mais precários e mal remunerados (Antunes, 2007). A necessidade de dar uma resposta urgente também para suas famílias de origem após o período universitário também é motivo de angústia e indecisões em relação ao seu planejamento de carreira, ocasionando um aumento do emprego precarizado para os egressos do ensino superior (Martins, 2006).

\section{Considerando a complexidade da carreira}

As sociedades contemporâneas possuem uma complexidade inigualável no que se refere ao planejamento de carreira e à preparação das pessoas para a inserção no universo profissional. 0 atual quadro socioeconômico conduz os jovens a uma visão cada vez mais pessimista sobre o seu futuro, pois a dificuldade de emprego também atinge os que possuem formação superior, o diploma universitário não é mais uma garantia de emprego. Há uma necessidade de saber cada vez maior, uma vez que o princípio ativo do trabalho imaterial não é mais a força física, e sim o conhecimento (Pochmann, 2000). Este exige maior qualificação do trabalhador e mudanças nos modelos educacionais.

A educação para o trabalho, como temos hoje, perde o sentido porque o trabalho muda a cada dia. Assim o lugar do diploma não é o mesmo em nossa sociedade, os jovens já sabem disto, quase que diariamente se deparam com colegas formados a procurar emprego.

Adentram a universidade, crentes de que o diploma é a solução para suas vidas, e ao final do curso percebem que a realidade não é bem esta, nesse contexto, a entrada no mercado do trabalho acontece cada vez mais tardiamente. Começam a vida profissional na busca do emprego e perguntam o que é preciso para se ter uma profissão: "Se não é mais somente o diploma que conta? É a experiência profissional? A prática? São os conhecidos 'QI' ou quem 
indica?". Há vinte anos o mais importante era o nome da faculdade. Hoje em dia o quadro mudou muito com a abertura das universidades no Brasil, e é preciso se atualizar e tomar decisões para planejar a carreira (Dowbor et al., 2004).

Ao buscar estágio ou empregos, enfrentam a pressão constante de familiares que investiram nos anos universitários, na esperança de obterem um retorno de mobilidade e ascensão profissional. Assim os formandos tecem suas escolhas sempre permeadas da angústia quanto ao futuro de suas decisões tomadas no presente (Dias \& Soares, 2009).

Neste contexto, na relação entre ensino superior e trabalho, existe a necessidade de escolher um caminho a seguir após a universidade, e, diante da imprevisibilidade do futuro e da incerteza, o amanhã se apresenta ao aluno como um mundo de possibilidades e de riscos (Martins, 2006). A questão da escolha profissional culmina no final da graduação, por ser um período de transição para o mercado de trabalho.

A universidade e a família devem propiciar ao egresso do ensino superior caminhos para o autoconhecimento, para a descoberta da identidade profissional, e fornecer informações qualificadas sobre o mercado de trabalho e sobre as opções de carreira futura. Ao estimular a reflexão sobre o Planejamento de Carreira se pretende influenciar e apoiar as universidades, famílias e o próprio aluno, no processo de transição (Soares, 2002).

O livro aborda temas como: a escolha da profissão, o conhecimento de si, os anos universitários, o mundo do trabalho, a inserção, o mercado de trabalho e técnicas para o planejamento de carreira. Uma segunda parte mais prática está voltada para exercícios de dinâmicas de grupo e apresenta técnicas que podem ser utilizadas em sala de aula. Neste sentido o planejamento de carreira é um processo de traçar objetivos e caminhos a serem trilhados, após o período universitário, capazes de dar suporte de segurança e o apoio psicológico necessário na transição (Dias \& Soares, 2009).

As orientadoras profissionais que trabalham no debate sobre a escolha da profissão encontram alunos com grande desconhecimento sobre o mundo e as carreiras de determinados postos ocupacionais. Muitas vezes sem noção sobre o mercado e as possíveis alternativas de carreira (Soares, Krawulski, Dias \& D’Ávila, 2007). Diariamente também observam alunos decididos e otimistas com o futuro, outros em crise na busca de um novo curso superior porque não encontram, mesmo ao final da graduação, a almejada satisfação profissional. Muitos estão confusos e temerosos sem saber se devem ou não sair da universidade, outros optam por continuarem estudantes, realizando inúmeras pós-graduações, especializações, mestrados e doutorados, muitas vezes sem se questionarem, mas simplesmente fazendo para retardar seu ingresso no mundo do trabalho, vivendo precariamente com bolsas de estudo e pesquisa.

É importante discutir as diferenças entre profissão e atividade ocupacional, entre trabalho e emprego. São muitas as diversidades no universo profissional a serem analisadas pelos jovens em início de carreira. 0 contexto é turbulento e nas últimas décadas, além das profissões, a família, o trabalho e a sociedade têm passado por uma série de transformações de ordem demográfica, social, econômica e cultural que trouxeram consequências de ordem objetiva e subjetiva (Dowbor et al., 2004).

Objetivamente o mercado profissional ainda é desconhecido para a maioria dos jovens e revela-se como assustador, pois a exposição à competição é grande e ainda existe uma necessidade de responder as expectativas familiares. Subjetivamente ser formando é viver em uma época de reflexões sobre o que fazer para ser um profissional: como montar seu currículo, como se apresentar a uma entrevista de emprego, como ser o escolhido?

Frente à vivência de discursos que alardeiam o desemprego, a indecisão sobre qual caminho seguir não é incomum. Existem muitas maneiras de construir um projeto profissional para superar as barreiras impostas, mas para construí-lo, é necessário driblar uma permanente insegurança e um sentimento de "não saber o que fazer quando sair da faculdade". A Classificação Brasileira de Ocupações (CBO) tem, atualmente, 2.422 ocupações cadastradas, mas este número muda a cada ano, já que surgem novas ocupações e outras deixam de existir lentamente.

Mercados como o de informática e administração apresentam sinais de saturação, ou seja, muitos profissionais disponíveis para poucas vagas. Mas há outros que estão em expansão, têm vagas, mas não existem profissionais para o trabalho como no caso dos bibliotecários. A cada época mudam-se as ofertas e as demandas das profissões, e acabam por gerar a necessidade de outros cursos de formação superior como é o caso da hotelaria na área de prestação de serviços (Dowbor et al., 2004). 
Deve o profissional da área pesquisar constantemente para conhecer as oscilações e alterações e procurar antever quais serão as profissões do futuro. Vivenciamos uma época de mutações, muitas profissões estão desaparecendo, e outras vão surgindo com uma grande velocidade.

\section{Considerações finais sobre o planejamento de carreira}

No Brasil a transição envolve os jovens com idade produtiva, em um sentimento de vulnerabilidade e impotência quanto ao seu futuro profissional, principalmente frente a uma visão limitada e limitante do mercado de trabalho (Dutra, 2002). A prática do planejamento de carreira no Brasil tem sido iniciada com uma avaliação pessoal daquilo que o sujeito deseja para sua vida, sem perder de vista os aspectos conjunturais que influenciam nas escolhas. Como exemplificado nestas falas: "Eu não sabia quais eram minhas habilidades, achava que não tinha nenhuma, agora depois da participação no Planejamento de Carreira, sei que tenho habilidade para lidar com pessoas e que posso desenvolver a liderança no meu local de trabalho!". Essa aluna, de Sistemas de Informação, trabalhando em uma empresa de tecnologia, percebeu que, para desenvolver sua carreira na empresa, precisava desenvolver novas competências de liderança e comunicação que ainda não eram conhecidas por ela.

0 orientador profissional e o próprio sujeito que pretende realizar seu planejamento de carreira precisam estar atentos ao mercado. Conhecer as exigências, perfis profissionais e as novas demandas das organizações, assim como conhecer os seus próprios pontos fortes e trabalhar no sentido de minimizar os pontos fracos e desenvolver novas competências. 0 exercício grupal e clínico de trabalhar a ansiedade inicial de obtenção de emprego, fazendo uma dramatização das entrevistas e processos seletivos, tem ajudado os alunos a enfrentar os processos seletivos das grandes organizações. Como nos mostra este depoimento:

eu não sabia porque não conseguia passar nas dinâmicas de grupo que participava, agora sei que não é só o indivíduo que é avaliado mas a sua capacidade de trabalhar em equipe, creio que eu não passava porque era muito competitivo, e acabava fazendo tudo sozinho.
A partir das vivências desenvolvidas na disciplina, os alunos percebem que devem estar atentos aos seus comportamentos nos processos seletivos, pois as empresas buscam profissionais que saibam trabalhar em grupo.

Ao tratar da gestão de carreiras, é fundamental considerar não só as estruturas socioeconômicas, as características do mercado de trabalho e a cultura na qual a organização se instala, mas os sujeitos enquanto seres sócios históricos (Lane, 2001) e capazes de mudar sua trajetória profissional (Dias \& Soares, 2009). Assim, no atual contexto em que se encontram as organizações, deve haver uma preocupação em integrar a gestão das carreiras para assegurar a permanência das pessoas e a competitividade e permanência no mercado das próprias empresas (Antunes, 2007).

Aos alunos, no ato de realizar o planejamento de carreira individual, apresentam-se vários paradoxos para a tomada de decisões, porque o trabalho tem demandado cada vez menos empregos estáveis e bem remunerados (Antunes, 2007). Ao planejar suas carreiras, os alunos podem tomar em conta seu perfil pessoal e seus valores, e não serem dominados por preocupações essencialmente financeiras. E também deve-se observar a ética no trabalho, como nesta fala: "Fiz estágio em um órgão público, mas não gostei porque eles estavam dominados mais por interesses econômicos do que pelo bem estar da população ao readequar os equipamentos sociais da cidade". Essa aluna nunca havia pensado que o local de trabalho tem uma determinada cultura, e esta pode ferir seus princípios éticos. Após a realização de seu planejamento de carreira, buscou novas oportunidades de trabalho, condizentes com seus valores pessoais.

Os sistemas de formação profissional estão em crise (Dowbor et al., 2004, Frigotto, 1998). Assim, ao planejar a carreira, o aluno pode buscar outras competências, disciplinas eletivas, optativas ou cursos que lhes permitam ampliar sua área de atuação. Observa-se na prática da orientação profissional o horizonte de expectativas profissionais se ampliarem quando o aluno passa a conviver com outras áreas de formação e esta experiência de trabalho grupal é gratificante. Se as carreiras têm sido marcadas pela instabilidade e descontinuidade na progressão (Chanlat, 1996; Frigotto, 1998), deve-se preparar os alunos para momentos de transição ao longo da vida profissional. 
Dutra (2002) aborda que as sociedades industrializadas configuraram uma política de emprego que é extremamente excludente e que a carreira é dependente de aberturas profissionais oferecidas. No que se refere a aberturas profissionais o planejamento de carreira ensina técnicas de networking e ferramentas de busca ativa pelo emprego além da inserção e colocação no mercado. Ao assumir a responsabilidade pelo seu planejamento de carreira, os sujeitos constroem uma crítica à questão do emprego na divisão social do trabalho e são orientados à busca de um trabalho com sentido e significado pessoal em suas vidas, para além do emprego.

As pessoas só se tornaram referencial de competitividade para as empresas no Brasil no início dos anos noventa embora muitas realizassem experiências na gestão de pessoas na década de 1980, pouca atenção foi dada à gestão nas filiais. Quando foi realizada uma pesquisa com profissionais de nível superior em 1993, observou-se que somente $2 \%$ da amostra haviam pensado de forma estruturada na própria carreira, o que revela ações pouco ativas sobre o desenvolvimento profissional (Dutra, 2002). 0 planejamento de carreira para as pessoas oferece instrumentos e metodologia para a estruturação de desenvolvimento profissional e pessoal. Para as empresas oferece conceitos e ferramentas para o gerenciamento do Recursos Humanos de forma estratégica, para a integração e harmonização do conjunto de políticas e práticas de administração de pessoas e da organização.

A prática do planejamento de carreiras na universidade tem buscado a integração das expectativas, interesses, motivações e interpretações que o sujeito faz da sua escolha durante a sua vida profissional. A principal mudança na natureza do trabalho é a sua transformação de material para imaterial, e na sociedade do trabalho imaterial, os limites entre o tempo de trabalho e o de não trabalho se diluem.

Assim a intensificação e a extensão do trabalho geram um aumento da produtividade e de riqueza que ainda não se reflete na qualidade de vida do trabalhador, mas que deve nos orientar para a busca de um trabalho com sentido em nossas vidas para além do capital. Segundo Antunes, "Sabe-se que a humanidade teria condições de se reproduzir socialmente, em escala mundial, se a produção destrutiva fosse eliminada e a produção social fosse voltada não para a lógica do mercado, mas para a produção de coisas socialmente úteis. Trabalhando poucas horas do dia, o mundo poderia reproduzir-se de maneira não destrutiva, instaurando um novo sistema de metabolismo societal"(Antunes, 2007, p. 172).

0 planejamento de carreira e a reflexão sobre diversas áreas e opções de trabalho podem promover a agilidade decisória na escolha do futuro profissional do jovem, levando a clareza de objetivos a serem perseguidos e as direções preferenciais pensadas a longo prazo para sua vida pessoal e profissional.

A universidade se distingue de qualquer outro tipo de instituição de ensino por ser o locus privilegiado para implantar o planejamento de carreira. Um território no qual os participantes interagem, desenvolvendo e adquirindo conhecimentos e habilidades com o objetivo de entender e agir sobre a realidade que os cerca. $E$ este processo resulta não apenas na capacitação da técnica e/ou na orientação profissional dos alunos para desempenhar suas atividades no seio da sociedade, mas deve proporcionar uma visão global desta realidade e de suas capacidades de transformação desta sociedade.

\section{Referências}

Antunes, R. (2007). Adeus ao trabalho? Ensaio sobre as metamorfoses e a centralidade no mundo do trabalho (12a ed.). São Paulo: Cortez.

Chanlat, J. (1996). 0 indivíduo na organização: Dimensões esquecidas. São Paulo: Atlas.

Dias, M. S. L., \& Soares, D. H. P. (2009). Planejamento de Carreira: Uma orientação para estudantes universitários. São Paulo: Vetor.

Dowbor, L., Furtado, O., Trevisan, L., \& Silva, H. (2004). Desafios do trabalho. Petrópolis: Vozes.

Dutra, J. S. (2002). Gestão de carreiras. In M. T. L. Fleury. As pessoas nas organizações. São Paulo: Gente.

Ferreti, C. J. (1988). Opção trabalho: Trajetórias ocupacionais de trabalhadores das classes subalternas. São Paulo: Cortez.

Ferreti, C. J. (2004). Considerações sobre a apropriação das noções de qualificação profissional pelos estudos a respeito das relações entre trabalho e educação. Revista Educação \& Sociedade, 25(87), 401-422. 
Ferreti, C. J. (1989). Uma nova proposta de orientação profissional. São Paulo: Cortez.

Fonseca, T. F. (2007). Tecnologia, trabalho e educação: Perspectivas, estratégias e trajetórias dos jovens no mercado de trabalho informacional. Recuperado em 20 fev. 2010, em http://en.scientificcommons.org/ tatiana_fonseca_vinha

Frigotto, G. (1998). A produtividade da escola improdutiva. São Paulo: Cortez.

Lane, S. M. (2001). A psicologia social e uma nova concepção do homem para a psicologia. In W. Codo, \& S. M. T. Lane (Org.). Psicologia Social: 0 homem em movimento (pp. 10-19). São Paulo: Brasiliense.

Martins, C. B. (2006). 0 ensino superior brasileiro nos anos 90. São Paulo em Perspectiva, 14(1), 41-60.

Nunes, E. (2006). Notícia: 53\% dos formados no país trabalham em outras áreas. Folha de São Paulo, 11 set. p. 1.

Pochmann, M. (2000). A batalha pelo primeiro emprego. São Paulo: Publisher Brasil.
Soares, D. H. P. (2002). A escolha profissional do jovem ao adulto. São Paulo: Summus.

Soares, D. H. P., Krawulski, E., Dias, M. S. L., \& D’Ávila, G. T. (2007). Orientação profissional em contexto coletivo: Uma experiência em pré-vestibular popular. Psicologia: Ciência e Profissão, 27(4), 746-759.

Sparta, M. (2003). O desenvolvimento da orientação profissional no Brasil. Revista Brasileira de Orientação Profissional, 4(1-2), 1-11.

Sposito, M. P. (1989). (Coord.). 0 trabalhador estudante, um perfil do aluno do curso superior noturno. São Paulo: Loyola.

Super, D. E. (1957). The psychology of careers. New York: Harper \& Row.

Vygotsky, L. S. (2000). Pensamento e linguagem (2a ed.). São Paulo: M. Fontes. 
